\title{
Patient's Dietary Beliefs and Behaviours in Inflammatory Bowel Disease
}

\author{
Jeanne H. M. de Vries ${ }^{a}$ Milou Dijkhuizen ${ }^{a}$ Petra Tap ${ }^{c}$ Ben J.M. Witteman ${ }^{a}$ b \\ ${ }^{a}$ Division of Human Nutrition and Health, Wageningen University, Wageningen, The Netherlands; ${ }^{b}$ Department \\ of Gastroenterology and Hepatology, Gelderse Vallei Hospital, Ede, The Netherlands; ${ }^{C}$ Crohn and Colitis Ulcerosa \\ Patient Association the Netherlands (CCUVN), Woerden, The Netherlands
}

\begin{abstract}
Keywords
Crohn's disease - Ulcerative colitis - Inflammatory bowel disease - Nutrition · Patient's perspective
\end{abstract}

\begin{abstract}
Background: The inflammatory bowel disease (IBD) is a chronic lifelong inflammation that may affect the entire gastro-intestinal tract in Crohn's disease and the colon in ulcerative colitis (UC). Diet plays an important role in IBD patients and many of them follow strict diet restriction in order to reduce complaints and prolong remission intervals. The aim of this study was to assess dietary beliefs, dietary behaviour and nutrition knowledge in Dutch adults with IBD to enable considering the patient's perspective on dietary advice. Methods: A self-administered online questionnaire assessing general characteristics, dietary beliefs and behaviour, nutrition knowledge and sources and dietary advice was devised. The questionnaire was distributed to members of the Dutch Crohn and UC patient association of whom 294 participated in the study. Results: Fifty-nine per cent of the patients valued nutrition to be either more or equally important compared to medication for their treatment and $62 \%$ believed diet to be more important in influencing the disease course. Sixty-two per cent reported to be successful in controlling disease symptoms through dietary adaptations. Avoiding certain foods was preferred over eating more ben-
\end{abstract}

eficial foods or following specific diets ( 77 vs. $57 \%$ and $48 \%$ respectively). Dietary supplements were used by $68 \%$ of the IBD patients. Although over $71 \%$ had received dietary advice mainly by dieticians, $81 \%$ stated that the main source of their nutritional knowledge related to IBD was their own experience. Conclusion: A subgroup of IBD patients considered diet to be a more important and successful managing tool than medication to relieve their disease symptoms.

(c) 2018 The Author(s)

Published by S. Karger AG, Basel

\section{Introduction}

Inflammatory bowel disease (IBD) is a lifelong chronic inflammation of the entire gastro-intestinal tract in Crohn's disease (CD) and of the colon in ulcerative colitis (UC) $[1,2]$. The disease course is characterised by periods of active disease and remission $[1,2]$. Three important factors in the pathogenesis of IBD, the intestinal microbiota, the immune system and the epithelial barrier function, can be modulated and controlled by diet $[1,2]$. Diet was found to affect the quality of life of IBD patients substantially [3-7], and modifying diet appeared to be a concrete tool for patients to manage their IBD $[3,7]$. IBD is heterogeneous in nature, so it has been proven to be hard to establish one specific dietary guideline for all IBD pa-

\section{KARGER}

E-Mail karger@karger.com www.karger.com/ddi
(C) 2018 The Author(s) Published by S. Karger AG, Basel

Karge

Open access

This article is licensed under the Creative Commons AttributionNonCommercial-NoDerivatives 4.0 International License (CC BYNC-ND) (http://www.karger.com/Services/OpenAccessLicense). Usage and distribution for commercial purposes as well as any distribution of modified material requires written permission.
Dr. Jeanne H.M. de Vries

Division of Human Nutrition and Health, Wageningen University

Helix building (124), Stippenweg 4, 6708 WE Wageningen

PO Box 17, NL-6700 AA Wageningen (The Netherlands)

E-Mail jeanne.devries@wur.nl 
tients $[3,8]$, and the types of food that are tolerated largely vary between patients $[7,9]$. Access to proper dietary advice is an essential part of dietary self-management in IBD [10]. However, patients learn about their food tolerances and intolerances by trial and error $[7,10]$ rather than under the guidance of a health professional. This creates the risk of (micro) nutrient deficiencies in case of uninformed or badly informed food avoidance and strict diets. Moreover, there is no guarantee that the best possible measures are taken to control the bowel disorder. There is, however, evidence that the effectiveness of personal diets could be improved by guidance of a professional dietary IBD service [9]. As a first start, it is important to learn more about current practices and beliefs of IBD patients with respect to their diet. Therefore, the aim of this study was to gain insight into the IBD patient's beliefs to what extent diet plays a role in their bowel disorder and the dietary changes they take to limit or avoid disease symptoms.

\section{Materials and Methods}

\section{Study Design and Participants}

A self-administered questionnaire was designed based on literature and filled out by IBD patients. In total, 5,338 patients were approached through newsletters sent by the Dutch Crohn and UC Patient Association. They could participate in the study if they were 18 years or older and diagnosed with either CD or UC. After the period for filling out the questionnaire had ended, responses of 324 participants were received. Twenty-four participants did not fully complete the questionnaire and were therefore excluded. Two participants were excluded because of implausible age and 4 others because of unclear diagnosis. Statistical analysis was performed on data of 294 participants.

\section{Questionnaire}

The questionnaire was developed after reviewing literature on IBD patient's dietary habits, beliefs, therapies and attitudes [3-7, 9, 11-19]. Based on this literature study, relevant topics for the questionnaire were identified. In addition, the draft questionnaire was thoroughly discussed with the dietician of the Dutch Crohn and UC Patient Association (PT) and an IBD patient, and modified because of practical aspects and face validity.

The questionnaire included 37 close-ended questions, which were divided into 4 sub-domains: general characteristics of the participants, dietary beliefs, eating behaviour and nutrition knowledge, and dietary advice. Answer options were made as complete as possible to ensure that important factors were not missed. The questionnaire was constructed in such a way that it took less than $30 \mathrm{~min}$ to fill out. The questionnaire was made in a digital format, using Qualtrics (https://www.qualtrics.com), posted on the website of the Dutch Crohn and UC Patient Association, and distributed by a monthly digital newsletter to their members over a 4 -week period. As the questionnaire was not personally distributed and neither name nor contact information was asked, the identities of the participants remained anonymous. The questionnaire can be found in Appendix I.

\section{Statistical Analysis}

The data were entered and analysed in IBM SPSS Statistics version 22 [20]. Descriptive statistics provided a first insight into the data collected. Proportions for categorical variables are expressed as percentages. The Cronbach's alpha test was performed to check the internal consistency and specifically the coherence of the variables forming the sub-domain dietary beliefs of the questionnaire. The chi-square test of independence was used to perform bivariate comparisons of nominal categorical variables, specifically to test differences across IBD type, gender and disease duration between the groups that had the disease either less than 10 years or 10 years or more. If the chi-square test showed significance, the phi correlation and Cramer's V post-tests were used to determine how strong the association was in a $2 \times 2$ or larger table respectively. $p<0.05$ was considered statistically significant.

\section{Ethical Considerations}

This research followed the ethical standards of human studies as established by the Declaration of Helsinki and the law protection personal data of the Netherlands. Ethics approval was not required. All patients gave written informed consent.

\section{Results}

\section{Baseline Characteristics}

Baseline characteristics of the study population are summarised in Table 1. Of the 294 IBD patients almost 3 quarters were female. Approximately half of the patients had UC and the other half had CD. The age range was $18-79$ years and more than $60 \%$ of the patients were $>40$ years old. A majority of almost 3 quarters reported to be in remission. The IBD patients were approximately equally distributed over the 4 categories of disease duration. The patients were most often treated with Mesalazine followed by immunosuppressives, then biologicals, and finally corticosteroids; almost $13 \%$ did not take any medication.

\section{Dietary Beliefs}

The IBD patients' dietary beliefs are presented in Table 2. More than $60 \%$ of the patients did not think diet is the most important cause of their IBD. In case of a relapse, this was still little over $40 \%$. However, $40 \%$ of all patients indicated that they can end a relapse faster by adapting their dietary intake. As for future perspective, the opin- 
Table 1. Baseline characteristics of the 294 participants

\begin{tabular}{lc}
\hline Variables & $n(\%)$ \\
\hline Gender & \\
Female & $211(71.8)$ \\
Male & $83(28.2)$ \\
Age, years & \\
$\quad 18-40$ & $105(35.7)$ \\
$>40$ & $189(64.3)$ \\
Disease type & \\
UC & $148(50.3)$ \\
CD & $146(49.7)$ \\
Disease activity & \\
Remission & $214(72.8)$ \\
Transitional stage & $53(18.0)$ \\
Relapse & $27(9.2)$ \\
Disease duration, years & \\
$\quad \leq 5$ & $71(24.1)$ \\
$\quad 6-10$ & $76(25.9)$ \\
$11-20$ & $79(26.9)$ \\
$\geq 21$ & $68(23.2)$ \\
Medication & \\
Mesalazine & $123(41.8)$ \\
Immunosuppressives & $117(39.8)$ \\
Biologicals & $71(24.1)$ \\
Corticosteroids & $48(16.3)$ \\
No medicine & $38(12.9)$ \\
Other medication & $36(12.2)$ \\
\hline
\end{tabular}

UC, ulcerative colitis; CD, Crohn's disease.

ions of the patients seemed to be divided. Approximately one third expected to gain more control over their IBD through diet, one third did not believe so and one third did not know. A majority of over $60 \%$ reported to be successful in controlling their disease symptoms through dietary adaptations, half of whom only during remission and about half almost always. Nearly $60 \%$ of the patients valued diet to be either more or equally important compared to their medicine. More than $60 \%$ believed IBD decreases appetite, mainly only during relapse. During remission the appetite was evaluated by over $80 \%$ to be good or very good.

\section{Dietary Behaviour}

A summary of the dietary behaviour of the IBD patients is shown in Table 3. Of the 294 participants less than half reported to have followed a special diet for their IBD. In contrast, $76.5 \%$ omitted foods in order to reduce disease symptoms. Abdominal pain and cramps were most often believed to be reduced followed by diarrhoea, relapse and fatigue $(88.0,68.9,39.6$, and $26.2 \%$ of the par-

Patient's Dietary Beliefs and Behaviours in IBD ticipants respectively). It was found that $56.7 \%$ of the participants consumed certain foods more frequently if they expected a beneficial effect on their disease symptoms. Abdominal pain and cramps were thought to improve most often, followed by diarrhoea, fatigue and relapse $(77.9,66.9,38.7$, and $36.8 \%$ of the participants respectively). Other diet and lifestyle adaptations included regular meal times (65.2\% of the participants), sports and exercise $(60.8 \%)$, more frequent smaller portions $(42 \%)$ and relaxation $(41 \%)$. Dietary supplements were used by $67.7 \%$ of the patients. The main reasons were to improve health (42.3\%) and reduce fatigue (31.3\%). Pre- and probiotics were used by a quarter of the IBD patients and the main reasons were to reduce disease symptoms and improve health.

Foods that were most commonly avoided to reduce disease symptoms are listed in Table 4 . Spicy foods were avoided by $74.7 \%$ of the respondents, followed by strongly seasoned foods, carbonated drinks, milk and other dairy products $(69.8,56.4$, and $51.6 \%$ respectively).

Foods that were consumed more often for their beneficial effects on disease symptoms are listed in Table 5. The most common food that was consumed more by $56.2 \%$ of the participants was wholemeal bread, followed by tea, leafy vegetables, fatty fish and poultry $(46.7,43.8,42.0$, and $38.9 \%$ respectively).

\section{Nutrition Knowledge and Dietary Advice}

Almost $81 \%$ of the patients stated that the main source of their nutrition knowledge related to their IBD was based on own experience; the Internet came second, followed by the dietician and the treating medical specialist in the hospital (37.2, 25.3, and 23.9\% respectively). Over $60 \%$ of the patients have had dietary advice concerning their IBD, mostly from a dietician and the medical specialist at the hospital. Of the 181 participants who had received dietary advice, more than $70 \%$ were satisfied with the advice.

No statistically significant differences in dietary beliefs, behaviour and knowledge were found between UC and CD patients. Compared to men, women were more likely to value dietary therapy as equally important as their medical treatment ( $p=0.048)$. Furthermore, women tended to avoid foods and use dietary supplements more often than men $(p=0.046)$. Disease duration was not associated with any of the variables tested. Only, a significant association between disease duration and dietary advice was found ( $p=0.023)$; the longer the patients had IBD the more likely it was that they have had dietary advice. 
Table 2. The dietary beliefs of the 294 IBD patients

\begin{tabular}{|c|c|c|c|c|c|}
\hline \multirow[t]{2}{*}{ Questions } & \multicolumn{5}{|c|}{ Answers, $n(\%)$} \\
\hline & yes & no & \multicolumn{3}{|l|}{ I do not know } \\
\hline $\begin{array}{l}\text { Do you believe that nutrition is the } \\
\text { most important cause of your IBD? }\end{array}$ & $38(12.9)$ & $187(63.6)$ & \multicolumn{3}{|l|}{$69(23.5)$} \\
\hline $\begin{array}{l}\text { Do you believe that nutrition plays an } \\
\text { important role in causing relapse? }\end{array}$ & $98(33.3)$ & $122(41.5)$ & \multicolumn{3}{|l|}{$74(25.2)$} \\
\hline $\begin{array}{l}\text { Do you believe that you can end a } \\
\text { relapse faster with adapted nutrition? }\end{array}$ & $119(40.5)$ & $65(22.1)$ & \multicolumn{3}{|l|}{$110(37.4)$} \\
\hline \multirow{2}{*}{$\begin{array}{l}\text { Do you expect to gain more control over } \\
\text { your IBD through nutrition in the future? }\end{array}$} & $85(28.9)$ & $111(37.8)$ & \multicolumn{3}{|l|}{$98(33.3)$} \\
\hline & Always & $\begin{array}{l}\text { Only during } \\
\text { relapse }\end{array}$ & $\begin{array}{l}\text { Only during } \\
\text { remission }\end{array}$ & Never & $\begin{array}{l}\text { I do not adapt } \\
\text { nutrition }\end{array}$ \\
\hline \multirow{2}{*}{$\begin{array}{l}\text { Are you successful in controlling your } \\
\text { disease symptoms by adapting your } \\
\text { nutrition? }\end{array}$} & $80(27.4)$ & $14(4.8)$ & $88(30.1)$ & $57(19.5)$ & $53(18.2)$ \\
\hline & $\begin{array}{l}\text { More } \\
\text { important }\end{array}$ & $\begin{array}{l}\text { Equally } \\
\text { important }\end{array}$ & $\begin{array}{l}\text { Less } \\
\text { important }\end{array}$ & Minor role & $\begin{array}{l}\text { Not } \\
\text { important }\end{array}$ \\
\hline \multirow{2}{*}{$\begin{array}{l}\text { What is the importance of nutrition } \\
\text { compared to your medicine? }\end{array}$} & $36(12.3)$ & $137(46.9)$ & $71(24.3)$ & $39(13.4)$ & $9(3.1)$ \\
\hline & Yes & $\begin{array}{l}\text { Only during } \\
\text { relapse }\end{array}$ & $\begin{array}{l}\text { Only during } \\
\text { remission }\end{array}$ & No & No opinion \\
\hline Do you believe that your IBD & $58(19.7)$ & $125(42.5)$ & $1(0.3)$ & $106(36.1)$ & $4(1.4)$ \\
\hline decreases your appetite? & Very poor & Poor & Fair & Good & Very good \\
\hline $\begin{array}{l}\text { How would you indicate your appetite } \\
\text { during remission? }\end{array}$ & $2(0.7)$ & $13(4.4)$ & $24(8.2)$ & $101(34.5)$ & $153(52.2)$ \\
\hline $\begin{array}{l}\text { How would you indicate your } \\
\text { appetite during relapse? }\end{array}$ & $51(17.5)$ & $127(43.5)$ & $56(19.2)$ & $41(14)$ & $17(5.8)$ \\
\hline
\end{tabular}

IBD, inflammatory bowel disease.

\section{Internal Validity Questionnaire}

The Cronbach's alpha coefficient of internal consistency for the 9 dietary beliefs items was 0.629 , which is considered to be adequate.

\section{Discussion}

To our knowledge, the dietary habits and beliefs of the IBD population in the Netherlands have never been described before. This study aimed to make an inventory of the perspectives of Dutch IBD patients with respect to their diet. The Dutch IBD population generally did not consider diet to be the cause of their IBD. However, specific foods were considered to cause or end a relapse of disease earlier. Manipulation of diet was considered to be an important managing tool to reduce disease symptoms and the majority of patients valued diet to be equally or even more important than medical treatment. Omitting detrimental foods was found to be a more frequently used way to use diet as a tool, compared to following special diets or consuming specific foods. Furthermore, most patients took dietary supplements to add to their diet. In addition to the dietary adaptations, sports and exercise and relaxation were part of the lifestyle adaptations that IBD patients most fre- 
Table 3. Dietary behaviour of 294 IBD patients

\begin{tabular}{|c|c|c|}
\hline \multirow[t]{2}{*}{ Questions } & \multicolumn{2}{|c|}{ Answers, $n(\%)$} \\
\hline & yes & no \\
\hline Have you followed a diet for your IBD? & $140(47.6)$ & $154(52.4)$ \\
\hline Do you omit foods in order to reduce disease symptoms? & $225(76.5)$ & $69(23.5)$ \\
\hline \multicolumn{3}{|l|}{ Disease symptoms that are reduced by omitting foods } \\
\hline Abdominal pain/cramps & $198(88.0)$ & \\
\hline Diarrhoea & $155(68.9)$ & \\
\hline Relapse & $89(39.6)$ & \\
\hline Fatigue & $59(26.2)$ & \\
\hline \multicolumn{3}{|l|}{ Do you eat more of certain foods that have a beneficial effect } \\
\hline on disease symptoms? & $166(56.7)$ & $128(43.3)$ \\
\hline \multicolumn{3}{|c|}{ Disease symptoms that are improved by eating more of certain foods } \\
\hline Abdominal pain/cramps & $127(77.9)$ & \\
\hline Diarrhoea & $109(66.9)$ & \\
\hline Fatigue & $63(38.7)$ & \\
\hline Relapse & $60(36.8)$ & \\
\hline \multicolumn{3}{|l|}{ Nutrition and lifestyle adaptations to reduce disease symptoms } \\
\hline Regular meals & $191(65.2)$ & \\
\hline Sports/exercise & $178(60.8)$ & \\
\hline More frequent smaller portions & $123(42.0)$ & \\
\hline Relaxation (mindfulness/meditation) & $120(41.0)$ & \\
\hline Do you use food supplements? & $199(67.7)$ & $95(32.3)$ \\
\hline \multicolumn{3}{|l|}{ Reason for supplement use } \\
\hline Improve health & $149(42.3)$ & \\
\hline Reduce fatigue & $110(31.3)$ & \\
\hline Reduce symptoms & $45(12.5)$ & \\
\hline Prevent relapse & $21(6.0)$ & \\
\hline Other reason & $27(7.7)$ & \\
\hline Do you use (foods enriched with) pre- and probiotics? & $78(26.5)$ & $216(73.5)$ \\
\hline \multicolumn{3}{|l|}{ Reason for pre- and probiotics use } \\
\hline Reduce symptoms & $48(61.5)$ & \\
\hline Improve health & $44(56.4)$ & \\
\hline Prevent relapse & $31(39.7)$ & \\
\hline Reduce fatigue & $22(28.2)$ & \\
\hline Other reason & $14(17.9)$ & \\
\hline
\end{tabular}

quently made. The majority of IBD patients have had dietary advice concerning their bowel disorder. In our IBD population, a great majority stated that the main source of their nutritional knowledge was their own experience.

In order to fully evaluate the findings of our study, a few strengths and weaknesses of the research need to be discussed. One strength of the research was the rather large study population of $n=294$ from rural and urban parts in the Netherlands, with a similar number of UC and CD patients. In the Netherlands, it is estimated that over 80,000 people have IBD of whom almost $60 \%$ have UC and 40\% CD [21]. Another strength was the exten- siveness of the questionnaire. In this way, a lot of information was gained and this enabled to make a clear profile of IBD patients and their dietary beliefs, behaviour and knowledge. Many questions in the questionnaire had multiple response options to make answers as complete as possible and to ensure that important factors were not missed. A possible weakness in our study was that the questionnaire was validated only for the questions on dietary beliefs, and that internal consistency of these questions was only adequate. However, although the questionnaire may have room for improvement, we still think that it has generated a lot of valuable dietary information about the IBD patients. 
Table 4. List of the most often avoided foods reported by 225 IBD patients

\begin{tabular}{lr}
\hline Foods & $n(\%)$ \\
\hline Spicy foods & $168(74.7)$ \\
Strongly seasoned foods & $157(69.8)$ \\
Carbonated drinks & $127(56.4)$ \\
Milk and dairy products & $116(51.6)$ \\
Energy drinks & $111(49.3)$ \\
Deep-fried foods & $105(46.7)$ \\
Alcoholic drinks & $104(46.2)$ \\
Cabbages & $84(37.3)$ \\
Pork & $83(36.9)$ \\
Processed meat & $82(36.4)$ \\
Coffee & $72(32.0)$ \\
Pastries & $71(31.6)$ \\
Sweets & $67(29.8)$ \\
Citrus fruits & $64(28.4)$ \\
Low-fibre bread & $64(28.4)$ \\
Legumes & $59(26.2)$ \\
Peanuts & $59(26.2)$ \\
\hline
\end{tabular}

Table 5. List of the most often more consumed foods reported by 164 IBD patients

\begin{tabular}{ll}
\hline Foods & $n(\%)$ \\
\hline High-fibre bread & $91(56.2)$ \\
Tea & $76(46.7)$ \\
Leafy vegetables & $71(43.8)$ \\
Fatty fish & $68(42.0)$ \\
Poultry & $63(38.9)$ \\
Exotic fruits & $62(38.3)$ \\
Pit fruits & $60(37.0)$ \\
Soft fruits & $60(37.0)$ \\
Non-leafy vegetables & $52(32.1)$ \\
Eggs & $51(31.5)$ \\
Legumes & $48(29.6)$ \\
Wholegrain rice & $48(29.6)$ \\
Nuts & $46(28.4)$ \\
White fish & $45(27.5)$ \\
Cabbages & $42(25.9)$ \\
\hline
\end{tabular}

Another possible limitation was that the questionnaire asked for dietary beliefs and behaviours both in the present and the past. This could have led to recall bias by the respondents.

Convenient sampling of the Dutch IBD population through the Dutch Crohn and UC Patient Association together with the fact that participation in this study was voluntary may have led to selection bias because the participants may already have been more interested in diet. Therefore, the importance of diet, that IBD patients in this study attach to it, may have been overestimated compared to the overall IBD population. The IBD population in this study turned out to be an older population than was expected. IBD is typically a disorder that starts and is usually worse at a younger age and becomes less severe when the patient gets older $[1,2]$. One explanation for the relatively older population could have been that the study population were IBD patients who were all members of the Dutch Crohn and UC Patient Association. Members of this association are indeed somewhat older than the usual IBD population. Furthermore, about 3 quarters of the study population were female, whereas UC occurs slightly more often in males than females and CD occurs only slightly more often in women than men [21]. Possible explanations could have been that women are more willing to participate in these types of studies or that women are more interested in nutrition than men. As we have found some differences in the outcome measurements between women and men, over- representativeness of women may have affected the results of our study. On the other hand, as still 83 men participated in our study, we were able to identify relative differences between genders.

The findings in this study are generally in line with the findings of other studies in this field. In concordance with Zallot et al. [4], patients did not believe that diet is the cause of their bowel disorder. Furthermore, patients believed that nutrition can influence the bowel disorder in such a way that it may prevent or end relapse faster and may reduce disease symptoms [4]. The most common behaviour to reduce disease symptoms was the avoidance of certain foods, followed by eating more of particular foods and then following special diets. This suggests a preference of patients not to follow strict diets, but rather excluding foods that may give problems or consuming more of foods that are considered beneficial. This was also found by Jowet et al. [15] in an UC population. The most commonly omitted foods were spicy foods, strongly seasoned foods, carbonated drinks, dairy products, energy drinks, deep-fried foods, and alcoholic drinks. These foods were also found in other food intolerance and exclusion studies $[4,9,11,13,15,19]$. Due to the design of this study, it cannot be stated whether these foods do actually worsen the bowel inflammation or just give a flare-up of symptoms. Furthermore, the most avoided foods are the foods that could cause ab- 
dominal discomfort in non-IBD people [11, 13, 15]. Prospective follow-up studies should investigate any causal relationship between foods and the IBD disease course. Cabbages and legumes were both in the list of most avoided as well as in the list of more consumed beneficial foods. The same phenomenon was seen in the study by Triggs et al. [9], who found that the same foods that were detrimental in some were beneficial in others, hinting that personalised diets might be most effective in IBD. The most common foods that were consumed more frequently were whole wheat bread, tea, leafy vegetables, fatty fish, poultry, exotic fruits (such as banana and avocado), pit fruits (such as apples and pears) and soft fruits (such as strawberries and raspberries). Some of the foods that were reported to be beneficial in our study caused problems in other studies. These included whole wheat bread, pit fruits, fatty fish and leafy vegetables $[9,13,15]$. This suggests a cultural factor in dietary habits and beliefs, since the other studies were done in populations from the United States, United Kingdom and New Zealand. Zallot et al. [4] reported that most of their subjects were not aware that their dietary behaviour could cause (micro) nutrient deficiencies. In our study, $>65 \%$ of the IBD patients took dietary supplements mainly to improve their health, indicating some awareness of possible (micro) nutrient deficiencies. Furthermore, Zallot et al. [4] reported that less than half of their subjects benefitted from dietary advice, while in our study, the patients who had received advice, over $70 \%$, were satisfied with it. Triggs et al. [9] showed that only $4 \%$ of their subjects reported to achieve complete success in controlling their disease symptoms by modifying their diet, whereas in our study, this was $27 \%$. Furthermore, Triggs et al. [9] found that avoiding foods by their subjects was not based upon their own recognition of adverse symptoms but rather on external advice. In our study population, it was found that the main source of nutritional knowledge was, according to the patients themselves, their own experience. This new fact prompts IBD patients with a nutritional demand to be supervised and treated by a professional. Tomar et al. [22] also concluded that proper dietary counselling is required in these patients to prevent malnutrition. From our results, however, it seems that finding a good diet for IBD patients is combining patient's own experiences (personalized diet) with external advice by a professional. This gives a fair success rate in controlling disease symptoms, since $>60 \%$ reported to be successful. Approximately half were always successful and the oth- er half were successful only during remission. Moreover, the majority of the respondents in our study consider nutrition to be equally important and even more important than their medical treatment. While Zallot et al. [4] and Vagianos et al. [19] found different dietary beliefs and behaviour according to IBD type, our study did not find this difference. However, in our study, there were some statistically significant differences according to gender. Compared to men, women were more likely to avoid certain foods, take supplements and value nutrition as important as their medical treatment.

Regarding the results of this study, there is more valuable information to be gained from the IBD patient's dietary knowledge. Studies recording the food consumption of patients in detail could provide more information on what is helpful for IBD patients. Although personalised diets may be of value, it may be more practical to categorize subgroups of IBD patients that may benefit from a certain diet. This applies for instance for severity of disease or disease location, for which some pattern of food intake or avoidance exists that may relieve disease symptoms. If this were to be the case, it might be possible to classify newly diagnosed IBD patients, so they would not have to find out their personal tolerances and intolerances from scratch.

In conclusion, the IBD patient's perspective on nutrition is that it has an important value, not necessarily to prevent the disease but rather as a tool in daily life to manage the symptoms. Although the dietary changes taken are not clear-cut changes and differ from person to person, a subgroup of patients do believe to benefit from their dietary actions. Therefore, we speculate that patients should be encouraged to take due note of their diet and learn from their own and other patients' experiences, preferably supported by professional advice.

\section{Disclosure Statement}

The authors declare no conflicts of interest.

\section{Author Contribution}

M.D., B.J.M.W., and J.H.M.V. designed the study; M.D. collected, analysed the data, and drafted the manuscript; P.T. was involved in the recruitment of the participants; J.H.M.V. and B.J.M.W. finalized the manuscript. All authors read and approved the final manuscript. 


\section{Appendix}

(Q1) What is your age?

(Q2) What is your gender?

(Q3) I have the following type of IBD: UC, CD, Other

(Q4) Where in your GI tract is your CD located?

(Q5) Where in your bowel is your UC located?

(Q6) Where in your bowel is your inflammation located?

(Q7) How long have you had your bowel disorder?

(Q8) Do you have medication for your IBD? If yes, what medication?

(Q9) Did you have surgical intervention for your IBD?

(Q10) What is the stage your IBD is in at the moment?

(Q11) Have you been diagnosed, aside from IBD, with food al-

lergies, food intolerances or irritable bowel syndrome?

(Q12) Do you believe nutrition is the most important cause of your IBD?

(Q13) Are you following or have you ever followed a diet for your IBD? If yes, which diet?

(Q14) Do you believe that nutrition plays an important role in causing periods of relapse?

(Q15) Do you intentionally avoid foods to reduce your disease symptoms?

(Q16) Which foods do you intentionally avoid to reduce your disease symptoms?

(Q17) What symptoms do you think of reducing when omitting the previously indicated foods?

(Q18) Do you believe that you can end a relapse sooner with nutritional adaptations?
(Q19) Do you intentionally eat more of certain foods to relieve your disease symptoms?

(Q20) Which foods do you intentionally eat more in order to relieve your disease symptoms?

(Q21) What do you think you have to improve when eating more of the previously indicated foods?

(Q22) What do you change in your nutrition and lifestyle to reduce your disease symptoms?

(Q23) Are you successful in controlling your disease symptoms by adapting your nutrition?

(Q24) What is the importance of nutrition compared to your medicine?

(Q25) Do you use food supplements (vitamins, minerals, iron, fish oils)?

(Q26) Why do you use food supplements?

(Q27) Do you use (foods enriched with) pre- and probiotics?

(Q28) Why do you use (foods enriched with) pre- and probiotics?

(Q29) Do you believe that your IBD decreases your appetite?

(Q30) How would you assess your appetite during remission?

(Q31) How would you assess your appetite during relapse?

(Q32) What is the source of your nutritional knowledge concerning your IBD?

(Q33) Did you receive or are you receiving nutritional advice concerning your IBD?

(Q34) What is the source of your nutritional advice?

(Q35) Are you satisfied with the nutritional advice?

(Q36) Why are you not satisfied with the advice?

(Q37) Do you expect to gain more control over your IBD through nutrition in the future?

\section{References}

1 Magro F, Gionchetti P, Eliakim R, Ardizzone $S$, Armuzzi A, Barreiro-de Acosta M, Burisch J, Gecse KB, Hart AL, Hindryckx P, Langner C, Limdi JK, Pellino G, Zagórowicz E, Raine T, Harbord M, Rieder F; European Crohn's and Colitis Organisation [ECCO]: Third European evidence-based consensus on diagnosis and management of ulcerative colitis. Part 1: definitions, diagnosis, extra-intestinal manifestations, pregnancy, cancer surveillance, surgery, and ileo-anal pouch disorders. J Crohns Colitis 2017;11:649-670.

2 Harbord M, Eliakim R, Bettenworth D, Karmiris K, Katsanos K, Kopylov U, Kucharzik T, Molnár T, Raine T, Sebastian S, de Sousa HT, Dignass A, Carbonnel F; European Crohn's and Colitis Organisation [ECCO]: Third European evidence-based consensus on diagnosis and management of ulcerative colitis. Part 2: current management. J Crohns Colitis 2017;11:769-784.

3 Fletcher PC, Schneider MA: Is there any food I can eat? Living with inflammatory bowel disease and/or irritable bowel syndrome. Clin Nurse Spec 2006;20:241-247.

4 Zallot C, Quilliot D, Chevaux JB, Peyrin-Biroulet $\mathrm{C}$, Guéant-Rodriguez RM, Freling E, Collet-Fenetrier B, Williet N, Ziegler O, Big- ard MA, Guéant JL, Peyrin-Biroulet L: Dietary beliefs and behavior among inflammatory bowel disease patients. Inflamm Bowel Dis 2013;19:66-72.

5 Fletcher PC, Jamieson AE, Schneider MA, Harry RJ: “I know this is bad for me, but...": a qualitative investigation of women with irritable bowel syndrome and inflammatory bowel disease: part II. Clin Nurse Spec 2008; 22:184-191.

6 Fletcher PC, Schneider MA, Van Ravenswaay, Leon Z: I am doing the best that I can!: living with inflammatory bowel disease and/ or irritable bowel syndrome (part II). Clin Nurse Spec 2008;22:278-285.

7 Jamieson AE, Fletcher PC, Schneider MA: Seeking control through the determination of diet: a qualitative investigation of women with irritable bowel syndrome and inflammatory bowel disease. Clin Nurse Spec 2007;21:152-160.

8 Sartor RB: Mechanisms of disease: pathogenesis of Crohn's disease and ulcerative colitis. Nat Clin Pract Gastroenterol Hepatol 2006;3: 390-407.

9 Triggs CM, Munday K, Hu R, Fraser AG, Gearry RB, Barclay ML, Ferguson LR: Dietary factors in chronic inflammation: food tolerances and intolerances of a New Zealand cau- casian Crohn's disease population. Mutat Res 2010;690:123-138.

10 Lomer MC: Dietary and nutritional considerations for inflammatory bowel disease. Proc Nutr Soc 2011;70:329-335.

11 Ballegaard M, Bjergstrøm A, Brøndum S, Hylander E, Jensen L, Ladefoged K: Self-reported food intolerance in chronic inflammatory bowel disease. Scand J Gastroenterol.1997;32: 569-571.

12 Brown AC, Rampertab SD, Mullin GE: Existing dietary guidelines for Crohn's disease and ulcerative colitis. Expert Rev Gastroenterol Hepatol 2011;5:411-425.

13 Cohen AB, Lee D, Long MD, Kappelman MD, Martin CF, Sandler RS, Lewis JD: Dietary patterns and self-reported associations of diet with symptoms of inflammatory bowel disease. Dig Dis Sci 2013;58:1322-1328.

14 Hou JK, Lee D, Lewis J: Diet and inflammatory bowel disease: review of patient-targeted recommendations. Clin Gastroenterol Hepatol 2014;12:1592-1600.

15 Jowett SL, Seal CJ, Phillips E, Gregory W, Barton JR, Welfare MR: Dietary beliefs of people with ulcerative colitis and their effect on relapse and nutrient intake. Clin Nutr 2004;23: 161-170. 
16 Kane S: What physicians don't know about patient dietary beliefs and behavior can make a difference. Expert Rev Gastroenterol Hepatol 2012;6:545-547.

17 Richman E, Rhodes JM: Review article: evidence-based dietary advice for patients with inflammatory bowel disease. Aliment Pharmacol Ther 2013;38:1156-1171.

18 Spooren CE, Pierik MJ, Zeegers MP, Feskens EJ, Masclee AA, Jonkers DM: Review article: the association of diet with onset and relapse in patients with inflammatory bowel disease. Aliment Pharmacol Ther 2013;38:1172-1187.
19 Vagianos K, Clara I, Carr R, Graff LA, Walker JR, Targownik LE, Lix LM, Rogala L, Miller N, Bernstein $\mathrm{CN}$ : What are adults with inflammatory bowel disease (IBD) eating? A closer look at the dietary habits of a populationbased Canadian IBD cohort. J Parenter Enteral Nutr 2016;40:405-411.

20 IBM SPSS Statistics for Windows, Version 22.0. Armonk, NY: IBM Corp. Released 2013.
21 van den Heuvel TRA, Jonkers DM, Jeuring SFG, Romberg-Camps MJ, Oostenbrug LE, Zeegers MP, Masclee AA, Pierik MJ: Cohort profile: the inflammatory bowel disease limburg cohort (IBDSL). Int J Epidemiol 2015; $1-9$.

22 Tomar SK, Kedia S, Upadhyay AD, Bopanna S, Yadav DP, Goyal S, Jain S, Makharia G, Ahuja V, Singh N: Impact of dietary beliefs and practices on patients with inflammatory bowel disease: an observational study from India. J Gastroenterol Hepatol Open 2107; $15-21$. 